Summer 8-2019

\title{
Identifying Occupational Therapy Role for Individuals in Substance Abuse and Addiction Recovery Programs
}

Tyler Cruz

Universty of St. Augustine for Health Sciences

DOI: https://doi.org/10.46409/sr.FORS9739

Follow this and additional works at: https://soar.usa.edu/capstones

Part of the Occupational Therapy Commons

\section{Recommended Citation}

Cruz, T. (2019). Identifying Occupational Therapy Role for Individuals in Substance Abuse and Addiction Recovery Programs. [Doctoral project, University of St Augustine for Health Sciences]. SOAR @ USA: Student Capstone Projects Collection. https://doi.org/10.46409/sr.FORS9739

This Capstone is brought to you for free and open access by the Student Research at SOAR @ USA. It has been accepted for inclusion in Student Capstone Projects by an authorized administrator of SOAR @ USA. For more information, please contact soar@usa.edu, erobinson@usa.edu. 
IDENTIFYING OCCUPATIONAL THERAPY ROLE FOR INDIVIDUALS IN SUBSTANCE ABUSE AND ADDUCTION RECOVERY PROGRAMS

\author{
by \\ Tyler, Cruz \\ A Capstone Project Proposal Presented in Partial Fulfillment \\ of the Requirements for the Degree of \\ DOCTOR OF OCCUPATIONAL THERAPY
}

University of St. Augustine for Health Sciences

August, 2019 


\title{
IDENTIFYING OCCUPATIONAL THERAPY ROLE FOR INDIVIDUALS IN
}

SUBSTANCE ABUSE AND ADDUCTION RECOVERY PROGRAMS

\author{
by \\ Tyler Cruz \\ has been approved
}

August, 2019

\section{APPROVED:}

Susan MacDermott, OTD, OTR/L, Mentor and Doctoral Coordinator

Erin Schwier EdD, OTD, OTR/L, Program Director

ACCEPTED AND SIGNED:

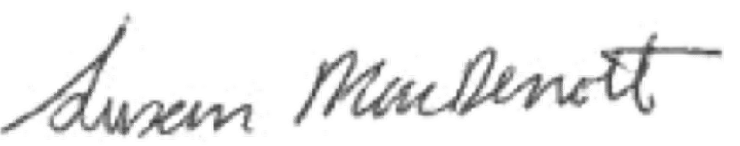

Susan MacDermott, OTD, OTR/L, Doctoral Coordinator

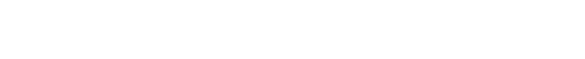

$\overline{\text { Erin Schwier, EdD, OTD, OTR/L, Program Director }}$ 


\section{Table of Contents}

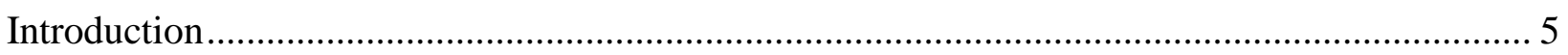

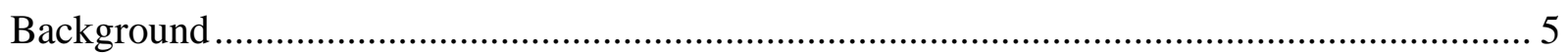

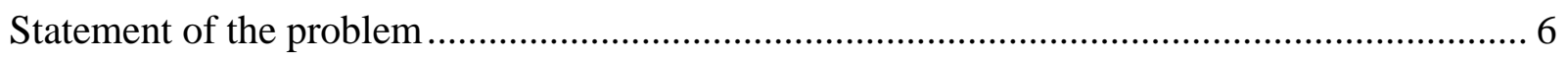

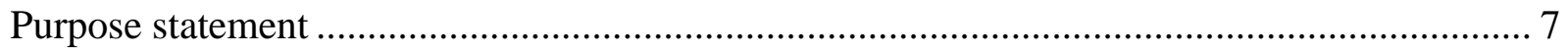

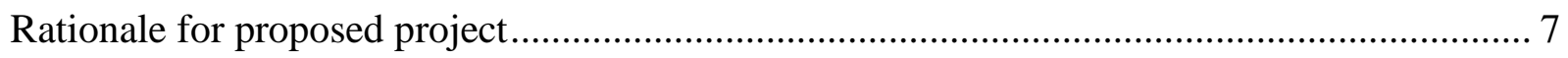

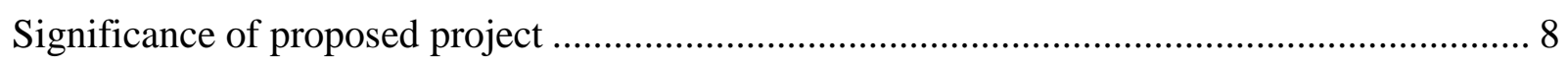

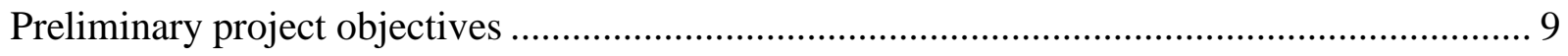

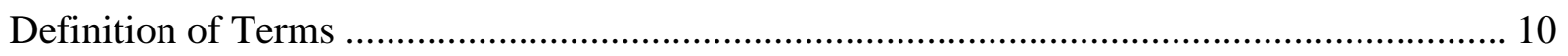

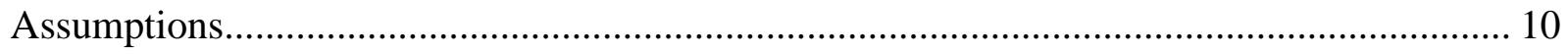

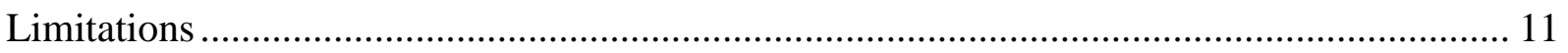

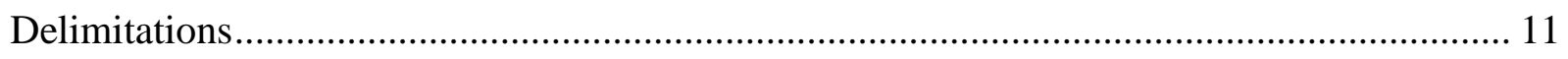

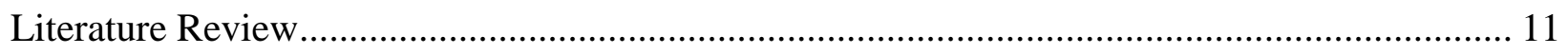

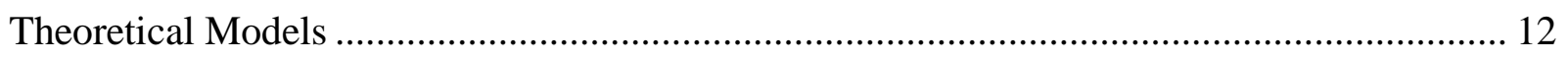

Current roles of Occupational Therapy in recovery programs ................................................ 13

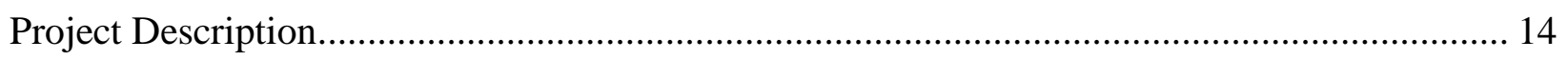

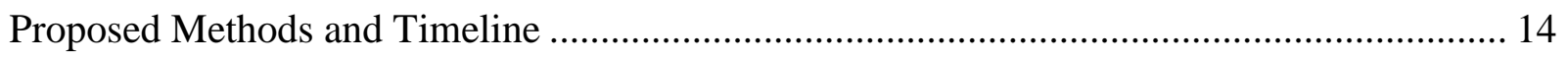

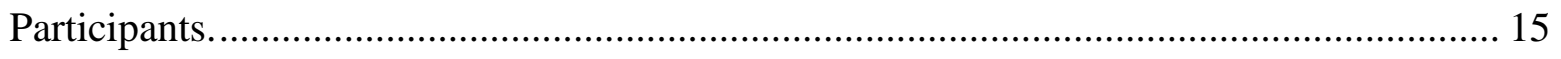

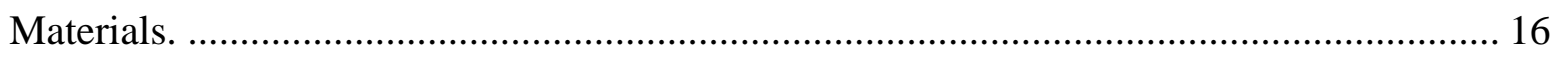

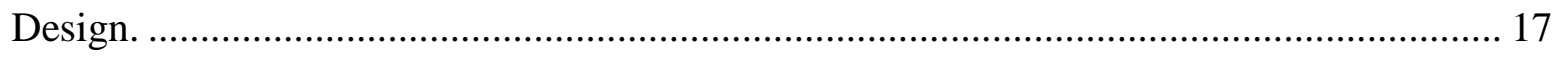

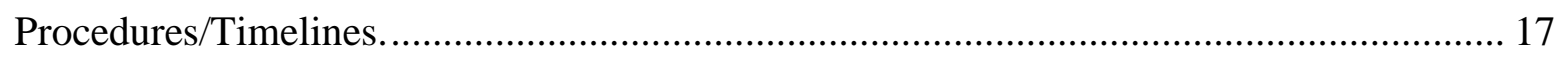

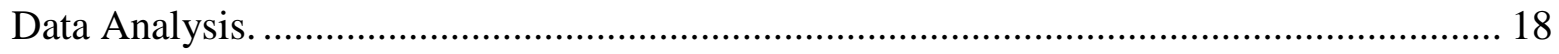

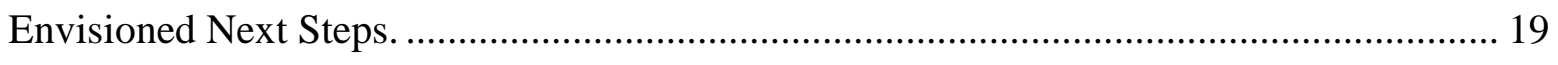




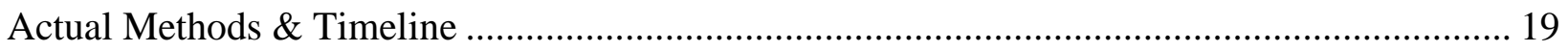

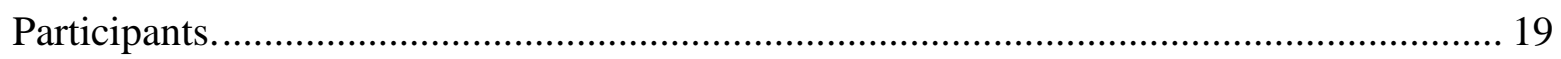

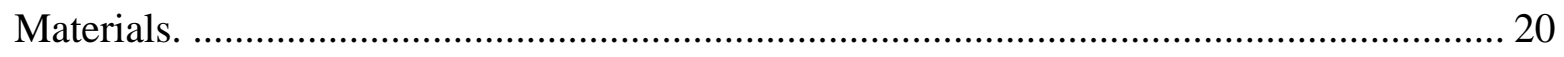

Procedure/Timeline ...................................................................................................... 20

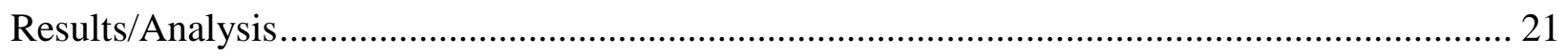

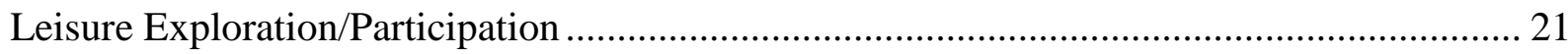

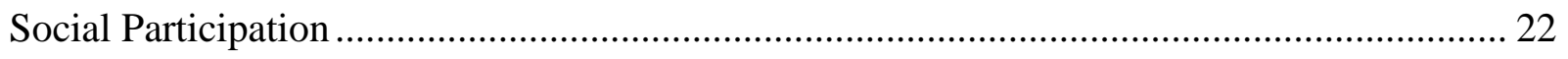

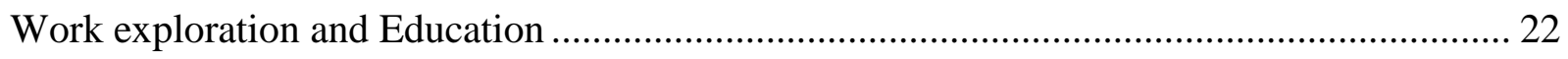

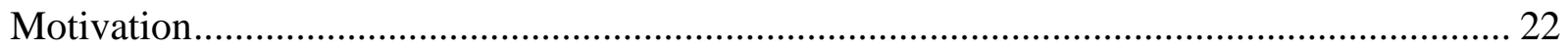

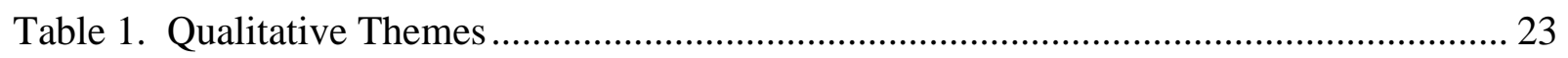

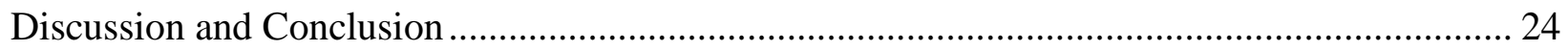

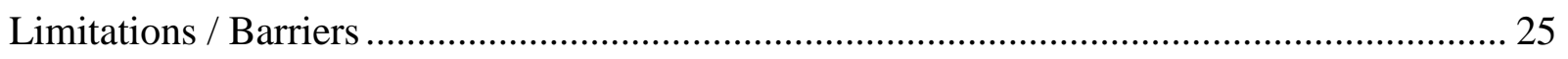

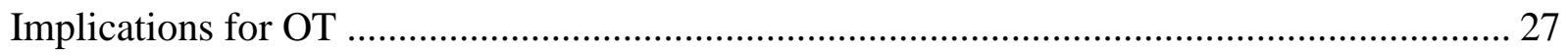

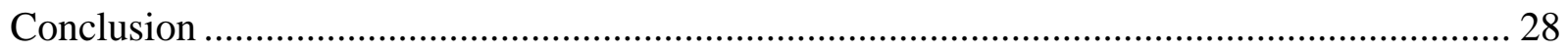

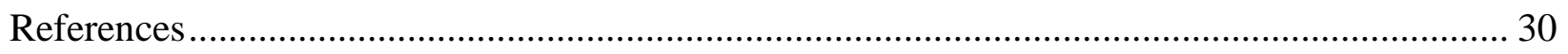

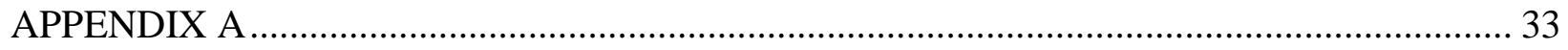

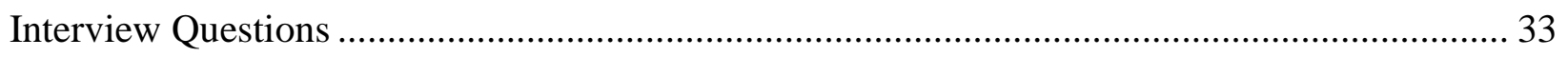

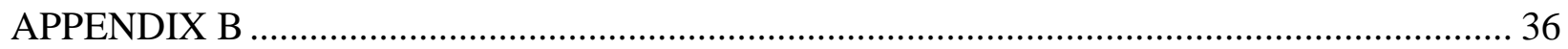

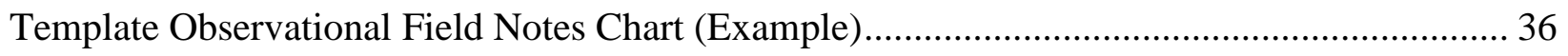

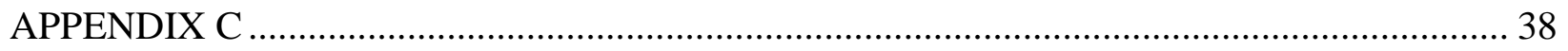

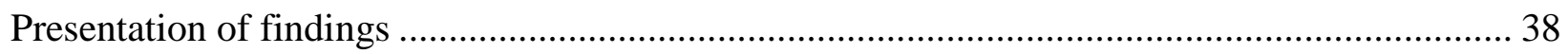

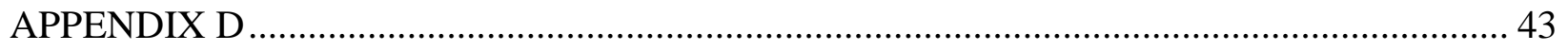

Evidence of Contact to other Residential Recovery Programs .................................................... 43 


\section{Introduction}

\section{Background}

There is a current public health issue that exists today in regards to individuals who abuse, or become addicted to drugs. The rate of drug overdoses has been steadily increasing resulting in, according to the Centers of Disease Control and Prevention, approximately 70,000 deaths in the United States in 2017 alone (2017). The utter amount of deaths from drug overdose in 2017 alone stood at a devastating 70,000 compared to 17,000 in 1999 to put it into comparison (CDC, 2017). Furthermore, the fact that many current substance abuse programs are seeing low success rates among their clients is concerning. Several studies suggest that approximately 80$90 \%$ of individuals can relapse within the first year of their recovery (Shaffer et al., 2004) and up to $60 \%$ are not satisfied with treatment in recovery programs and consequently discontinue services (Shumway et al. 2013 as cited in Wasmuth, Crabtree, \& Scott 2014). Substance abuse programs that emphasize a multidisciplinary approach may provide improved recovery outcomes as it implements treatment from a variety of different perspectives. For example, didactic interventions that typically entail skills training help individuals to learn new strategies however do not put those skills into practice during therapy (Wasmuth, Pritchard, \& Kaneshiro, 2016). In a recent study, an 18 year girl stated how “...it will be better if we can practice group stuff on the outside first...so that we can know it work and so that if I have questions I can ask." (Bell et al., 2015, p. 13) Putting newly learned skills from other didactic interventions into practice during treatment through activities of occupation (e.g. leisure, social, work activities) can improve quality of treatment services and ultimately improve recovery outcomes (Wasmuth, Pritchard, \& Kaneshiro, 2016). This further supports the idea that current substance abuse programs can 
benefit from an additional perspective and area of expertise that fills the gap in current substance use and addiction programs today.

\section{Statement of the problem}

These recent statistics described in the 'Background' section suggest that a multitude individuals either abusing drugs, or suffering from drug addiction, may not be getting the necessary treatment they need to prevent potential drug overdoses. Because of the increased rates of drug overdose and deaths in the country, the issue of substance abuse and addiction has become a serious public health issue that needs to be addressed. Substance abuse and addiction may very well result in being in and out of hospitals, correctional facilities, jails, or prisons. Recently, the development of laws and penalties related to drug use has resulted in approximately $50 \%$ of prisoners meeting criteria for drug abuse or dependence (Chandler, Fletcher, and Volkow, 2009). Moreover, substance abuse and addiction can cause disruptions and harm between family and friends as they experience the negative effects from abusing substances (Santana, \& Oliveira, 2017). Consequently, this has become a serious problem that affects many individuals that are in need of developing new habits, routines, and roles that will enable them to no longer abuse substances and participate in healthier occupations that allow them to be more productive members of society. Finally, occupational therapy does not appear to be well understood as a beneficial service to many recovery programs. According to a systematic review that examined occupational therapy intervention in the treatment of addiction, “...occupational therapy still plays a secondary role to more prominent disciplines... in many instances it is relegated to the role of entertainer..." (Rojo-Mota,Pedrero-Perez, \& HuertasHoyas, 2017, p.2). Rojo-Mota and colleagues further added that occupational therapists typically spend their time keeping patient's busy and occupying their time as opposed to utilizing 
occupations as a source for intervention (Rojo-Mota,Pedrero-Perez, \& Huertas-Hoyas, 2017); for that reason, occupational therapists are not often considered for a primary role to addiction treatment services.

\section{Purpose statement}

The purpose of the capstone project is to advocate for the need of occupational therapy within the substance abuse population. This capstone will attempt to concentrate on the issues that individuals face when abusing substances that affect their lifestyles, relationships with family and friends, roles, routines, and occupational participation. As an outcome this capstone will propose a role for occupational therapy in this setting and advocate for the occupational therapy profession in the rehabilitation and recovery of the substance abuse and addiction population.

\section{Rationale for proposed project}

The rational for the proposed project is that substance abuse is a pressing issue that can lead to individuals, including adolescent individuals, into jail, correctional facilities, hospitals, etc. Therefore, it is important to incorporate effective practices and treatment methods that will enable this population to more easily and efficiently practice healthier habits and routines by participating in meaningful occupations. Occupational therapy interventions within recovery programs can "...enable clients to foster engagement in meaningful occupations and activities and assists clients with planning and structuring their time to focus on constructive, meaningful activities and occupations which replace drug-related activities” (Bell et al., 2015, p. 11).

Several theoretical models have been proposed from previous studies that have shown promise as a basis for guiding intervention for individuals in recovery programs. The Model of Human Occupation (MOHO), a client centered model rooted an individual's motivation, habits, 
and performance capacity, has supported areas of occupational competence, occupational identity, and quality of life - all of which play important roles in the maintenance of recovery (Boisvert, Martin ,Grosek, \& Claire, 2008). To further support the implementation of this model, a study that used a non-randomized pretest-posttest design utilized the Occupational Performance History Interview, Version 2.0 (OHPI-II), an assessment tool derived from the MOHO model, as a means of collecting data related to an individual's volition, habituation, occupational performance, and environment (Martin, Bliven, \& Boisvert, 2008). The Peer Support Community model, implemented in a study by Boisvert, revealed improvements in participation, self-determination, and peer support within community activities; and the results of the study indicated a difference in relapse rates between non-participants of PSC and participants of PSC of $24 \%$ and $7 \%$ respectively. Additionally, a recent study theorized exploring addiction-as-occupation in a study that interviewed 10 participants for $60-75$ minutes. The results of the study showed that addiction can contribute to an individual's identity, motivations, and routines; and for a majority of individuals, provides meaning to their lives in spite of the negative health concerns it carries (Wasmuth, Crabtree, Scott, 2016). These theories will serve as a guide into exploring and identifying the occupational needs and potential interventions of individual's in current recovery programs.

\section{Significance of proposed project}

This capstone project seeks to contribute to the development of new practices and treatments available for the substance abuse population that can help them in forming new habits, roles, and routines. Additionally it can help individuals within a recovery process in returning to the community as productive members of society and engage in new healthy experiences that will lead healthier lifestyles. A recent article on occupational performance for 
individuals who abuse or are addicted to substances states how "...occupational therapists serve a major therapeutic role in substance abuse rehabilitation process by enabling clients to improve on work and social skills, develop healthy routines and habits, and engage in personal hobbies and experiences" (Martin, Bliven, \& Boisvert, 2008, p82). This project will contribute to current programming in correctional facilities, substance abuse programs, sober living homes, or other settings that serve individual's with substance abuse. Incorporating occupational therapy services and perspectives into current treatment options will enhance a collaborative effort in treating individuals within these settings.

\section{Preliminary project objectives}

These objectives will serve as a guideline when observing and interacting with the substance abuse population and gathering info that will further enforce an occupation based approach to treatment and the role of occupational therapy for this specific population.

Preliminary objectives include: 1) Describe options and treatment success for current substance abuse services 2) Analyze strengths and limitations to current substance abuse programming 3) Identify the common occupational needs of individuals with substance abuse concerns through observation of individuals in programs or community groups (correctional facility, AA meetings, outpatient programs, online forums) 4)Identify successful occupational therapy interventions for substance abuse through literature and interviews with OT's working in substance abuse settings. 5) Design and propose material to advocate for role of OT in substance abuse settings. 6) Successfully communicate potential role of OT to multiple substance abuse settings. 7) Evaluate effectiveness of proposal and summarize recommendations to adapt future communication. 


\section{Definition of Terms}

For the purpose of this project occupation will be defined as areas of life activities described in the Occupational Therapy Practice Framework that individuals engage in including but not limited to leisure, social participation, work, and education (AOTA, 2014). Occupational needs for this project will be defined as areas of occupation derived from the Occupational Therapy Practice Framework (i.e. leisure, social participation, work, education, rest and sleep etc.) that appear to be lacking or negatively affected; which will contribute to and encourage successful recovery. Occupation-based intervention is defined as interventions by which an occupation (i.e. areas of leisure, social participation, work, and education) or activities in preparation for occupation are performed. Treatment success will be defined as the effectiveness of a recovery program based on results of outcome measures specific to that program. Substance abuse settings for this project will refer to healthcare and community settings (e.g. correctional facilities, outpatient, community) in which programming is implemented specifically for individual's recovering from substance use and/or addiction. Saturation for this project refers to the point at which qualitative data becomes repetitive and there is a lack of new data or themes.

\section{Assumptions}

It is assumed that occupations have become negatively affected as a result of some degree of substance abuse or addiction. Moreover, data will be collected via observation and interviews based on the assumption that all responses are honest and truthful. It is highly probable that individuals will be unique to the type of substance they abuse or have become addicted to; however, inferences in identifying occupational needs and potential interventions for the population are based on the presumption that individuals in recovery can be grouped into similar occupational issues. 


\section{Limitations}

Limitations of the capstone project include data collection from various settings (i.e. correctional facilities, outpatient, online forums, etc.) where occupational needs may differ. Additionally, sites may have specific policies put in place that may limit access to individuals in recovery with substance use concerns. Another aspect that cannot be controlled for is the time in recovery the individual is currently in. For example, some individual's may be observed in the beginning stages of their recovery and others may be in a later stage of recovery or perhaps have been frequently in and out of recovery. Furthermore, it is possible that people in recovery are currently suffering from or have a history of other comorbid diseases, conditions, or health issues that cannot be controlled for. Lastly, observational data collection will likely be limited to the events in which researcher is present and does not control for additional events or incidences that occur outside of observed time period.

\section{Delimitations}

This capstone project will be limited to individual's currently in substance abuse and addiction recovery programs. Additionally, data collection will solely be focused on qualitative data obtained through observation and interviews from people in recovery. Data collection is to be obtained through multiple areas and sites that include correctional facilities, outpatient settings, and online forums.

\section{Literature Review}

There has been a reasonable amount of literature pertaining to substance abuse programming, and the current role of occupational therapy in recovery programs. Several themes derived from the literature describe theoretical models or frames of reference and current roles of occupational therapy in substance abuse programming. These themes serve as a guide to the 
potential direction of occupational therapy within recovery programs and expansion of current substance abuse and addiction programming.

\section{Theoretical Models}

Current literature has reviewed and implemented several theoretical models that serve as a foundation for guiding intervention and recovery programs. The Model of Human Occupation (MOHO) is a model that encourages engagement in occupations through developing self-concept and self-esteem as a major contributor to an individual's “....self-determination or proactive steps initiated by clients to direct and influence their own recovery process" (Boisvert et al., 2008, p.208). Boisvert et al. (2008) applied the concept of MOHO with the use of The Volitional Questionnaire 4.0 (VQ), an assessment tool designed to collect data regarding a client's motivation, in a study that examined the effectiveness of peer support in recovery programs. Despite that were no definitive trends identified in VQ data, the study revealed improvements in occupational competence, occupational identity, self-esteem, and quality of life. The literature support in the use and success of the MOHO model as a guide to intervention further supports occupational therapy as a beneficial services to recovery programs.

An additional theoretical model that was suggested introduced the idea of addiction as an occupation; stating that addiction can provide meaning and value to an individual's life despite its negative health consequences (Wasmuth et al., 2014). Wasmuth et al. (2014) looked into this theory further by collecting qualitative data through interviews of 10 different participants who had volunteered for the study. The results of the study revealed that addiction-as-occupation contributed to areas of identity, motivation, and routines. Furthermore, the study offered implications for occupational therapy in helping individuals to identify occupations that “...allow individuals to lose themselves in an activity... and facilitate development of self- 
mastery and self-efficacy" as an area of focus (Wasmuth et al., 2014, p. 612). To further support this implication, a recent study that looked at client perceptions of occupational therapy interventions, revealed a theme in their results that indicated "We taking the drugs away, but we need to give them something back in that place" (Bell et al., 2015, p.12). Helbig and Mckay (2003), one of the first researchers to explore addiction from an occupational perspective, stated that addiction is a "complex activity that alters an individual's occupational sphere" and is largely influenced by factors that include family and peer influence (Helbig \& Mckay, 2003 as cited in Rojo-Mota,Pedrero-Perez, \& Huertas-Hoyas, 2017).

Finally, the Peer Support Community (PSC) model is a model that focuses on maintaining abstinence from substance use and supports the prevention of relapse by taking active community roles that enable them to take control of the direction of their lives). This model served as a guide to a Peer Support Community program implemented in a study that found positive results in relapse rates in comparison to Peer Support Housing alone (Boisvert et al., 2008). The researchers also concluded from the results of this study, that "...community members are reaching out to each other and supporting each other" (Boisvert et al, 2008, p. 217). The various theoretical models that have been introduced and implemented may serve as a guide to establishing and solidifying a potential role for occupational therapists within recovery programs.

\section{Current roles of Occupational Therapy in recovery programs}

Occupational therapists working with recovery programs currently carry a variety of roles that they fill by addressing specific occupations with unique interventions. For example, occupational therapists working at a halfway house help individuals with life skills (e.g. stress and anger management, vocational exploration, work-related skills, leisure exploration, 
parenting, and antisocial behavior modification) training contributing to improvements in selfesteem and quality of life (Martin, Bliven, Boisvert, 2008). Furthermore, a systematic review revealed that several programs have targeted occupations and activities such as work, education, or exercise; in effort to establish consistency and regularity that brings structure to the individual's life (Leppard et al., 2018). Occupational therapists have also served as a facilitator role in coordinating community meetings, events, or activities that supports an individual's recovery through improvements in self-esteem, self-determination, and self-efficacy (Boisvert etal., 2008). The facilitator role in a study conducted by Boisvert et al. (2008) entailed acting as ..." a catalyst to facilitate community development, offer unconditional support and guidance when requested, and nudge just a bit to get community started" (Boisvert et al., 2008, p. 217). The current roles of occupational therapists within recovery programs suggests that recovery programs would benefit from an added perspective focused on life skills training, occupations, and coordination of activities/resources.

In summary, the theoretical models described in the evidence, act as a guide to intervention within recovery programs. Additionally, the current roles of occupational therapists in recovery programs indicate the potential role and benefits of an added perspective addressing occupational deficits for this population. The themes discussed will serve as a guide to this capstone project in further examining the occupational needs of individuals in recovery programs and identifying potential occupational therapy interventions.

\section{Project Description}

\section{Proposed Methods and Timeline}

This capstone project will focus on advocacy for the role of occupational therapy for those in recovery for substance abuse and addiction. This population is an emerging practice area 
for the occupational therapy profession as it can hold many benefits for the recovery process for an individual who is in recovery from addiction to substances. This capstone project will attempt to address the occupational needs and potential occupational therapy interventions of the population through literature review, direct observation of the population, interviews, etc. Occupational needs could include participation in meaningful activities such as self-care, work, leisure, and social activities. Lastly, this capstone project will involve an informative presentation at designated sites to educate and advocate for the potential OT role for this population.

\section{Participants.}

The population of this study will include adults (18 years or older) currently in substance abuse and addiction recovery programs. Participants will be obtained through convenience sampling, a sampling method that recruits individuals that meet inclusion and exclusion criteria as they become available (Portney \& Watkin, 2014). This sampling method will be used in an effort to gather participants on the basis of availability given the limited time constraints ( 14 weeks), treatment settings, and the number of clients in recovery programs. Recovery programs for this capstone project will be inclusive to three separate settings.

Core Civic is a correctional facility located in San Diego that accompanies individuals of various backgrounds including individuals with a possible history of substance abuse and/or addiction. At this location, participants will be recruited through asking the site supervisor for a list of names of individuals in a substance abuse and addiction recovery process or program.

Lasting Recovery is an outpatient treatment center located in San Diego that implements a multidisciplinary approach and emphasizes treatment from a holistic perspective to meeting the unique needs of their clients. In this particular setting, individuals will be in partial 
hospitalization programs that require an occupational therapy evaluation per facility policy. The on-site occupational therapist will be shadowed during OT sessions and observational field data will be recorded. In-depth interviews will be conducted with permission of the facility and consent from client. In the event that OT sessions alone do not provide a sufficient amount of clientele in comparison to other settings, the student will introduce the purpose of the capstone project and observe other available recovery groups if able.

Interfaith is an outpatient treatment center located in Escondido that holds a recovery program to support addiction recovery for homeless and low-income individuals. Various settings were selected for qualitative data collection for the purpose of garnering data from a variety of contexts (e.g. stage in recovery, comorbidities, socioeconomic status, etc.). To gather an adequate sample of appropriate participants, substance abuse and addiction groups will be observed; and case managers or site supervisors will be asked for a list of appropriate clients currently in the recovery process.

\section{Materials.}

This capstone project will include interview and observational data collection tools in effort to gather qualitative data. Interview questions are largely influenced by questions used by Wasmuth, Crabtree, and Scott (2014) in their qualitative study Exploring Addiction-asOccupation. Several questions have been modified accordingly for the appropriateness of this capstone project in identifying occupational needs. Additionally, interview questions will be guided through various categories of the Canadian Occupational Performance Measure (COPM) that include areas of leisure, work, play, and self-care. Observational data will be collected via field notes organized in a table that will include: date, time and place, occupations observed, 
environmental characteristics, learned skills, and words or phrases. See interview tools in Appendix A and observational data collection tools in Appendix B.

\section{Design.}

For this capstone project, an ethnographic approach to research will be used. At each of these three settings, qualitative data will be collected through observation and semi-structured interviews with clients to gain a deeper understanding of potential occupational needs and occupational therapy interventions. For this capstone project, a participant observation approach will be used to encourage participant interactions and engagement in program activities or discussions. Face to face interviews will be conducted upon permission and consent from the participant and facility. This capstone project does not control for the potential limitation that an individual or group of individual's cannot or refuse to be observed; for that reason, face to face interviews will be useful as an unobtrusive method of data collection for these individuals (Creswell, 2013). Handwritten notes of participant responses will be taken during interview sessions and immediately after in effort to ensure accurate data collection.

\section{Procedures/Timelines.}

The researcher will primarily be a participant observer to client interaction and engagement in specific program activities at a given setting (e.g. Lasting Recovery, Interfaith, or Core Civic). Observational data can be obtained as a third party observer or as a participant in program discussions and activities. In the case that the observer becomes a participant and is unable to record data, observations will be recorded in the field notes table (Appendix B) within one hour after observations hours are completed for that day to ensure data accuracy. Interviews for this capstone projects will be semi-structured and notes will be taken during and immediately after interviews. The observational and interview procedures listed above will occur across all 
settings with the assumption that facility policies and regulations allow for the data collection methods specific to this project. Because there is no current solidified role for occupational therapists in recovery programs, this capstone project will not include any form of program development or implementation; however, recommendations to recovery programming will be made while proposing material to various treatment settings.

Observation's and interview experiences may take place anywhere between 448 hours to 560 hours or until saturation occurs. The researcher will be present among designated settings 5 times per week for approximately 14 weeks collecting qualitative data. Capstone experiences will begin in late March 2019 and proceed until at least 448 hours have been completed (July 2019) by the researcher or until saturation occurs.

\section{Data Analysis.}

Data analysis for this project will consist of generating common themes gathered from observational and interview data that pertain to the impact of occupation. Analysis will consist of examining interview notes and observational data from field notes in attempt to obtain any commonalities that may include: words, phrases, language, occupations, and social or environmental contexts discussed that will serve as common themes for individuals in recovery programs. Adequate data for this capstone project will be determined when saturation occurs, or when data themes begin to repeat and there is a lack of new data from interview or observation experiences. Common themes derived from data will be presented and organized in the Appendix B observation tool; however, will not present all data collected, but rather the identifiable themes gathered after thorough analysis of qualitative data. Themes gathered from interview responses will be presented in an organized table with separated columns for treatment settings and themes. 


\section{Envisioned Next Steps.}

After adequate data collection has been obtained across all settings (Lasting Recovery, Interfaith, and Core Civic); material will be designed and proposed through a medium most convenient to treatment settings (e.g. presentation, educational materials such as pamphlets or poster boards, etc.) to advocate for the role of OT in substance abuse and addiction programming. A post-survey will be provided to substance abuse settings in effort to evaluate the effectiveness of the proposal and summarize recommendations to adapt future communication as necessary.

\section{Actual Methods \& Timeline}

This capstone experience shifted to focus on individuals in a residential recovery treatment setting; therefore, observation hours were completed entirely at Interfaith Community Services. This shift in focus was made due to the increasing amount of information gathered from the first 1-2 weeks of observation suggesting that individuals in residential treatment exhibited a higher level of occupational need (self-care, medication management, leisure, and social participation, etc.). For this reason, the capstone project focused entirely on the needs of the residential recovery program population.

\section{Participants.}

The participants of this capstone project included residents in the Recovery and Wellness program at Interfaith Community Services. In addition, before admission into the program, a large majority of the participants were homeless or held a lower socioeconomic status. A total of 33 participants, male and female, were admitted into the program during the capstone experience. However, 8of these participants were either removed from the program by staff or had voluntarily left the program. 


\section{Materials.}

The materials used for this capstone project included an observational field notes chart that was used to organize and analyze data in addition to interview questions. Also, notes were taken during observation experiences and a laptop to record data into the observational field notes tool every week using Microsoft Word. The observational field notes data table included columns for: date, location, environmental characteristics, occupations discussed or observed, words or phrases, and motivation. See observational data collection tool in Appendix B.

\section{Procedure/Timeline.}

The student conducted observation hours at Interfaith Community Services 5 days per week from April 1, 2019 to July 16, 2019. The student attended groups between the hours of 9a.m. to 4:30p.m. (Approximately 4-5 groups per day) and participated in group discussions when appropriate. Groups meetings took place on either the men's or women's common area, or in a large conference room to accommodate for a larger number of participants.

Participants were also interviewed in a separate and isolated room to avoid distraction and improve interview experiences. Semi-structured interviews were conducted for 10-15 minutes after participants had first completed at least 2-3 weeks of the residential program to allow time to adjust to environment, fellow participants, and staff. Interviews were stopped in mid-June due to the student not receiving the intended responses.

Data was recorded onsite in a spiral notebook and later organized electronically in a chart. Collected data included notes based on the observation chart in areas of: location, group activity or topic, environmental characteristics, areas of occupation, words or phrases, and motivation. As themes were analyzed, different themes were organized via different color highlights in an observational field notes chart. Areas of social participation were highlighted in 
yellow, areas pertaining to leisure were highlighted in light blue, and other less prominent themes were highlighted in light green (work and education).

Furthermore, as part of the preliminary objectives, the student conducted an interview via email with an occupational therapist working with the substance abuse and addiction population at Simple Recovery in Costa Mesa, California. This interview was conducted to gather further evidence of potentially successful occupational interventions currently being implemented within recovery programs. After a short interview with the occupational therapist, it was mentioned that groups often focus on leisure development in addition to other areas such as communication skills, team building, interview skills etc.

The student presented their capstone findings to Interfaith via a power point presentation. This presentation also included a leisure program outline for their additional benefit if they decided to follow up on presented information (See Appendix C). Additionally, the student reached out to other residential treatment programs within the areas of Riverside County, Orange County, and Los Angeles County. The student contacted numerous residential treatment programs of the purpose of the capstone project and requested the opportunity to provide information through a medium most convenient to their recovery program (See Appendix D).

\section{Results/Analysis}

\section{Leisure Exploration/Participation}

After careful data analysis and thematic coding, the first notable theme found through the capstone experience was leisure exploration and participation. The participants shared their need for exploring and participating in leisure with statements such as "boredom is a trigger for me... I need some activity in my life." Another participant noted that after completion of the program, how they "... have too much time on my hands." and expressed the desire to want to do 
something different. Furthermore, the student observed within group discussions numerous times how many participants were unable to answer the question "What do you like to do for fun?", or would respond with "I don't know." This observation may suggest that the participants perhaps did not want to share with the group, or more importantly, simply did not know.

\section{Social Participation}

A second prominent them that was revealed through data analysis, was the desire to find new sober and/or clean friends. Many participants verbalized the need to avoid previous friends, family, or acquaintances that continuously surround themselves with alcohol and other drugs. Also, a large number of participants expressed the desire to attend more AA and/or NA meetings to allow the opportunity to make new friends and build new relationships with individuals that share the same motivation and goal for long term sobriety. Gaining a sober network as a strong support system during their recovery process was an important aspect that many felt they needed in order to help them achieve long term sobriety.

\section{Work exploration and Education}

Although work exploration and education did not appear to be strong themes after data analysis, it is worth noting that the needs for these particular areas of occupation were expressed several times throughout the capstone experience. Several participants expressed the desire to find work and/or go back to school to pursue a career, "I would love to have a career, not just a job.” Additionally, participants had verbalized the importance of finding and securing a job before completion of the program for financial stability and for the ability to pay for their own housing.

\section{Motivation}


This capstone project was framed around the Model of Human Occupation (MOHO), a frame of reference rooted in an individual's volition (motivation), habituation (habits, roles, routines), and performance capacity. The results of the data analysis in regards to the significance of volition for this population were reflective of literature as several studies were guided in the MOHO model (Martin, Bliven, Boisvert, 2008). However, potential factors contributing to volition have not been revealed in previous studies. Throughout the capstone experience, volition appeared to be a strong contributing factor for a participant's engagement or disengagement in their recovery process. More specifically, placing a high value on family and children was shown to be a strong motivating factor driving the individual's recovery. The majority of the participants expressed their desire to spend time with their children or reconnect with family that they had lost in their addiction. Additionally, the support and success from fellow veteran participants of the program appeared to be a strong motivating factor for newly admitted participants. For these reasons, having strong values of family and success appeared to be influencing factors in driving the participant's recovery process.

Table 1. Qualitative Themes

\begin{tabular}{|l|l|}
\hline Themes & Examples \\
\hline $\begin{array}{l}\text { Leisure exploration / } \\
\text { participation }\end{array}$ & $\begin{array}{l}\text { Expressed the need to do something every week (activity) } \\
\text { "I need some activity in my life" } \\
\text { Expressed desire to add things to do on free time, “...it's our } \\
\text { responsibility" }\end{array}$ \\
\hline Social Participation & $\begin{array}{l}\text { Talking with peers is a distraction away from thoughts of using. } \\
\text { Important to gain a sober network and new group of friends } \\
\text { Desire to want to attend more meetings throughout the week to } \\
\text { meet new people } \\
\text { "I still don't have a job" }\end{array}$ \\
\hline Work Exploration
\end{tabular}




\begin{tabular}{|l|l|}
\hline Education & Need to find a job and secure a job while in program \\
\hline $\begin{array}{l}\text { Expressing the desire to return to school after completion of the } \\
\text { program } \\
\text { "I would love a career, not just a job" }\end{array}$ \\
\hline
\end{tabular}

\section{Discussion and Conclusion}

The purpose of this capstone project was to identify potential occupational needs for individuals suffering from substance abuse and addiction through literature review, observation and interview. Additionally, this project set to propose a potential role for the occupational therapy profession in various treatment settings; however the focus changed to specifically proposing roles for residential treatment centers given their specific needs.

The findings presented in this project support the idea that many individuals suffering from substance abuse and addiction display a need for meaningful leisure activities. The significance of leisure participation is supported by the likely presumption that individuals had previously spent most of their time either seeking or using substances which causes leisure time to pose as a potential trigger (Martin, Smith, Rogers, Wallen, \& Boisvert, 2011). Further, the results of this project are reflective of previous literature and the importance of meaningful activities in place of addiction and drug related activities (Bell et al., 2015) as it would enable the individual to "...lose themselves in an activity" that may help distract from thoughts of substance use and improve their self-esteem (Wasmuth et al., 201, p. 612). Participants from previous studies have expressed similar concerns in regards to leisure exploration and participation compared with the participants for this project. To further support this area as a need, after a brief interview with an occupational therapist, it was mentioned that groups typically focused on leisure development in addition to other areas such as communication skills, assertiveness training, team building, and interview skills. 
Furthermore, the results of this project highlight the importance of making new friends and connect with peers that are sober and/or clean and also place a high value on long term recovery. These findings may provide an explanation as to why a Peer Support Program was found to be successful in the reduction of relapse rates (Boisvert et al., 2008). The importance of peer support may also explain why a lack of social rehabilitation is one of the main causes for relapses and returning to other drug related activities such as seeking or selling drugs (Santana \& Oliveria, 2017). The social environment and support of the recovery community can be beneficial as a positive characteristic for an individual in recovery (Polcin et al., 2014). The need for the addiction population to engage in new and healthy relationships proves to be significant as it can provide the support system and social environment that one needs in order to enhance their recovery process and contribute to long term sobriety.

Although occupational areas of social participation and leisure appeared more frequently as prominent themes, work exploration and education also seemed to be important to participants. These results are further supported by the literature indicating the need for intervention in addressing areas of employment along with other areas that include but are not limited to positive support networks and aftercare services (Manuel, et al., 2017). Further, engagement in occupations of education and work strongly foreshadow positive outcomes due to lower rates of relapse and criminal activities (Manuel et al, 2017).

\section{Limitations / Barriers}

There were several limitations to this capstone project that include: lack of intended responses for participant interviews, small sample size, participants predominantly of lower socioeconomic status and/or homeless, and lack of variety in group topics, and lack of interviews with occupational therapists in recovery programs. 
The interview questions were designed to gain an idea of the engagement or disengagement in occupational areas such as ADL's, IADL's, leisure, and work. In addition, the intent of participant interviews was to gather relevant data on their roles, routines, environment, and motivation. Unfortunately, interview questions did not appear to garner responses related to the participant's current needs, but rather provided insight into what the participants do not need. For example, the majority of participants stated that they did not practice self-care during their addiction because it was not a priority; however practicing self-care while being in a recovery program did not appear to be an issue and participants demonstrated and verbally expressed their ability to engage in their ADL's and IADL's independently. It would have been recommended that the student modify interview questions during capstone experience in order to garner intended responses that would highlight important current occupational needs. Modifying interview questions to highlight occupational areas that appeared to be most important to participants (i.e. social participation, leisure, work, and education) and ensuring questions remain open ended would have been beneficial to gather intended responses.

This capstone project included 33 participants, 8 of which were individuals who had voluntary left the program, or were exited from the program for unspecified reasons. Due to the small sample size, the results of this project may not be generalizable to individuals suffering from substance abuse and/or addiction currently in other residential treatment programs.

Furthermore, a large majority of the participants were either homeless or held a low socioeconomic status before admission into the program. Therefore, the results revealed in this project may not be generalizable to individuals in other residential treatment programs where homeless is not often a concern or where there are different levels of socioeconomic status. 
The group topics discussed by group facilitators (i.e. clinical therapists, substance abuse counselors) included areas of shame and resilience, relapse prevention, anger management, recovery skills, process groups, and criminal addictive thinking. All topics were covered each week as part of the curriculum at the Interfaith Recovery and Wellness Program. Therefore, group topics were limited in its focus on areas of occupation; however; a number of groups (process, Q\&A, and rewired groups) were more semi-structured which allowed the opportunity for discussion among certain occupations as they arose.

Througha brief interview with an occupational therapist currently working in a recovery program, the therapist noted how groups can involve topics of leisure development and team building. Other topics addressed by the therapist in this setting include self-awareness, coping skill application, interview skills, and communication skills. However, it would have been beneficial for the student to gather more interventions that are currently being implemented by conducting additional interviews with occupational therapists in other treatment settings, particularly residential settings.

\section{Implications for OT}

The findings presented in this project reveal the potential needs of individuals recovering form addiction in residential treatment programs. Additionally, it suggests a role for the occupational therapy profession in residential treatment programs as a potential health professional or facilitator during an individual's transition from a 90-day residential treatment program into the community and aftercare such as outpatient treatment. This is supported by the occupational needs found with this capstone project that include social participation and leisure exploration and participation, in addition to less prominent themes of work exploration and education. Because occupational therapists are uniquely skilled in helping individuals in the 
areas of social participation and leisure; these findings suggest that there may very well be a place for occupational therapy in residential treatment programs.

Future areas of research and projects could include a qualitative review of a larger population of individuals within various residential recovery programs may help to expand and generalize the findings from this capstone project. According to literature, after completing a residential program approximately $14 \%$ of individuals attend outpatient programs and less than 50\% attend self-help groups after completing a residential program (Carter et al., 2008). A qualitative case study following individuals after completion of a residential treatment program and their transition into the community or potential outpatient treatment may provide further insight into whether these identified areas of need remain significant to the individual or change altogether. It is not entirely clear in what ways leisure exploration and participation, and social participation can be explored in the most effective way for individuals in a residential recovery program; therefore, future projects focusing on program development may be beneficial in order to establish a valid and reliable form of intervention from an occupational therapy perspective for individuals in residential recovery programs.

\section{Conclusion}

Several key findings from this project include the importance of exploring and participating in leisure activities in addition to engaging in social participation with a new group of friends or peers for individuals in residential recovery programs. Addressing these significant areas of need early during residential treatment may provide a solid foundation for a successful transition from residential treatment and out into the community. Additionally, understanding the factors that contribute to positive outcomes will assist treatment programs into making continual improvements that will enhance programming (Decker, Peglow, Samples, \& 
Cunningham, 2017). This capstone project sheds light on the potential role of occupational therapy within residential recovery programs. Furthermore, the findings strongly reflect conclusions from previous literature that occupational therapy services can help enable clients to practice social skills for increased social participation and engage in personal leisure activities and experiences (Martin, Bliven, \& Boisvert, 2008). 


\section{References}

American Occupational Therapy Association ( $3^{\text {rd }}$ Edition). (2014). Occupational therapy practice framework: Domain \& process. American Journal of Occupational Therapy, 68(Supplement_1).doi:10.5014/ajot.2014.68s1

Bell, T., Wegner, L., Blake, L., Jupp, L., Nyabenda, F., \& Turner, T. (2015). Clients' perceptions of an occupational therapy intervention at a substance use rehabilitation centre in the Western Cape. South African Journal of Occupational Therapy, 45(2), 10-14.

Boisvert, R. A., Martin, L. M., Grosek, M., \& Clarie, A. J. (2008). Effectiveness of a peersupport community in addiction recovery: Participation as intervention. Occupational Therapy International, 15(4), 205-220.

Carter, R. E., Haynes, L. F., Back, S. E., Herrin, A. E., Brady, K. T., Leimberger, J. D., ... \& Liepman, M. R. (2008). Improving the transition from residential to outpatient addiction treatment: Gender differences in response to supportive telephone calls. The American journal of drug and alcohol abuse, 34(1), 47-59.

Chandler, R. K., Fletcher, B. W., \& Volkow, N. D. (2009). Treating drug abuse and addiction in the criminal justice system: improving public health and safety. JAMA, 301(2), 183-190.

Creswell, J. W. (2013). Research design: Qualitative, quantitative, and mixed method approaches. Thousand Oaks: SAGA Pub.

Decker, K. P., Peglow, S. L., Samples, C. R., \& Cunningham, T. D. (2017). Long-term outcomes after residential substance use treatment: Relapse, morbidity, and mortality. Military medicine, 182(1-2), e1589-e1595.

Helbig, K., \& McKay, E. (2003). An exploration of addictive behaviours from an occupational perspective. Journal of Occupational Science, 10(3), 140-145. 
Leppard, A., Ramsay, M., Duncan, A., Malachowski, C., \& Davis, J. A. (2018). Interventions for women with substance abuse issues: A Scoping Review. American Journal of Occupational Therapy,72(2). doi:10.5014/ajot.2018.022863

Manuel, J. I., Yuan, Y., Herman, D. B., Svikis, D. S., Nichols, O., Palmer, E., \& Deren, S. (2017). Barriers and facilitators to successful transition from long-term residential substance abuse treatment. Journal of substance abuse treatment, 74, 16-22.

Martin, L., Bliven, M., \& Boisvert, R. (2008). Occupational performance, self-esteem, and quality of life in substance addictions recovery. OTJR: Occupation, Participation And Health, 28(2), 81-88. http://dx.doi.org/10.3928/15394492-20080301-05

Martin, L. M., Smith, M., Rogers, J., Wallen, T., \& Boisvert, R. (2011). Mothers in Recovery: An Occupational Perspective. Occupational Therapy International. doi:10.1002/oti.318 Opioid Overdose. (2018, December 19). Retrieved from https://www.cdc.gov/drugoverdose/data/statedeaths.html

Polcin, D., Mericle, A., Howell, J., Sheridan, D., \& Christensen, J. (2014). Maximizing social model principles in residential recovery settings. Journal of psychoactive drugs, 46(5), 436-443.

Portney, L. G., \& Watkins, M. P. (2014). Foundations of clinical research: Applications to practice. Harlow: Pearson Education.

Rojo-Mota, G., Pedrero-Pérez, E. J., \& Huertas-Hoyas, E. (2017). Systematic review of occupational therapy in the treatment of addiction: Models, practice, and qualitative and quantitative research. American Journal of Occupational Therapy, 71(5), 7105100030p17105100030 p11. 
Santana, C. J., \& Oliveira, M. L. (2017). Effects of drug involvement on long-term users' family members. Revista Da Rede De Enfermagem Do Nordeste, 18(5), 671-678. doi:10.15253/2175-6783.2017000500015

Shaffer, H. J., LaPlante, D. A., LaBrie, R. A., Kidman, R. C., Donato, A. N., \& Stanton, M. V. (2004). Toward a syndrome model of addiction: Multiple expressions, common etiology. Harvard review of psychiatry, 12(6), 367-374.

Wasmuth, S., Crabtree, J. L., \& Scott, P. J. (2014). Exploring addiction-as-occupation. British Journal of Occupational Therapy, 77(12), 605-613.

Wasmuth, S., Pritchard, K., \& Kaneshiro, K. (2016). Occupation-based intervention for addictive disorders: A systematic review. Journal of Substance Abuse Treatment, 62, 1-9. 
APPENDIX A

Interview Questions 
1) In what ways was your life different or the same before using?

2) In what ways did using affect your activities of daily living such as:

a. Self-care? (e.g. showering, getting ready etc.)

b. Eating?

c. Follow up question: How are you doing now? How are these activities affected now?

3) In what ways have using affected your ability to:
a. Care for others? (e.g. as a caregiver, parent, etc)
b. Manage finances?
c. Manage/maintain health?
d. Manage/maintain home?
e. Run errands/Shopping?
f. Sleep?

4) Describe the people, places, and/or activities that are most important to you right now. Are these the same from when you were using?

5) Do you work? If so, what do you do for work?

a. Do you find your work meaningful? Do you feel it contributes to your health? Or do you feel it is a risk factor for your health and sobriety?

6) What do you enjoy doing? Hobbies?

7) How are you currently spending your day from when you wake up to when you go to bed?

8) What sources of support do you feel you have right now?

a. Are you satisfied with this current support system? 
9) What do you find effective about the recovery program here?

10) Is there anything you personally, would like to address or work on in recovery programs?

11) What are you current roles (e.g. father, brother, son)?

a. How do you feel these roles have changed since using?

12) Optional Question: Tell me about what your addiction meant to you? What did it provide for you? 


\section{APPENDIX B}

Template Observational Field Notes Chart (Example) 


\begin{tabular}{|c|c|c|c|c|c|c|}
\hline DATES & $\begin{array}{l}\text { PHYSICAL } \\
\text { ENVIRONM } \\
\text { ENT (e.g. } \\
\text { time and } \\
\text { place) }\end{array}$ & $\begin{array}{l}\text { PROGRAM } \\
\text { ACTIVITY }\end{array}$ & $\begin{array}{l}\text { DISCUSSED } \\
\text { ENVIRONMENTAL } \\
\text { CHARACTERISTICS }\end{array}$ & $\begin{array}{l}\text { OBSERVED/DISCUSSD } \\
\text { OCCUPATIONS (only } \\
\text { inclusive to occupations } \\
\text { listed in OTPF) }\end{array}$ & $\begin{array}{l}\text { WORDS, PHRASES, } \\
\text { CONVERSATIONS }\end{array}$ & MOTIVATION \\
\hline $04 / 09 / 19$ & Interfaith & $\begin{array}{l}\text { Connections } \\
\text { Education - } \\
\text { Recovery }\end{array}$ & & $\begin{array}{l}\text { Expressed the need to do } \\
\text { something every week } \\
\text { (activity) }\end{array}$ & $\begin{array}{l}\text { "boredom is a trigger for } \\
\text { me" } \\
\text { "....add things on our } \\
\text { free time... add it with } \\
\text { stuff it's our } \\
\text { responsibility." }\end{array}$ & $\begin{array}{l}\text { Value family relationships: } \\
\text { Using is not beneficial for } \\
\text { Family }\end{array}$ \\
\hline $05 / 31 / 19$ & Interfaith & $\begin{array}{l}\text { Stages of } \\
\text { Change }\end{array}$ & $\begin{array}{l}\text { Social environment can } \\
\text { be a trigger for relapse }\end{array}$ & & $\begin{array}{l}\text { "worried about } \\
\text { complacency...I still } \\
\text { don't have a job." }\end{array}$ & \\
\hline $06 / 12 / 19$ & Interfaith & Process Group & & $\begin{array}{l}\text { Talking with peers is a } \\
\text { distraction away from } \\
\text { thoughts of substance abuse }\end{array}$ & $\begin{array}{l}\text { "...finding the time to } \\
\text { go out and do stuff" }\end{array}$ & \\
\hline 07/08/19 & Interfaith & Recovery Skills & $\begin{array}{l}\text { Red flag thought - } \\
\text { grocery shopping, } \\
\text { running errands }\end{array}$ & $\begin{array}{l}\text { First thing after completing } \\
\text { program - make new } \\
\text { friends }\end{array}$ & $\begin{array}{l}\text { For fun now } \\
\text { clean/sober? - “' I don't } \\
\text { know." }\end{array}$ & $\begin{array}{l}\text { "It's hard to summon } \\
\text { motivation when trying to get } \\
\text { through each moment of } \\
\text { withdrawal" }\end{array}$ \\
\hline
\end{tabular}




\section{APPENDIX C}

Presentation of findings 
IDENTIFYING OCCUPATIONAL THERAPY ROLE FOR INDIVIDUALS IN RESIDENTIAL RECOVERY PROGRAMS

By: Tyler Cruz OTD/S

University of St. Augustine for Health Sciences

Interfaith Recovery and Wellness Program

OCCUPATIONAL THERAPY
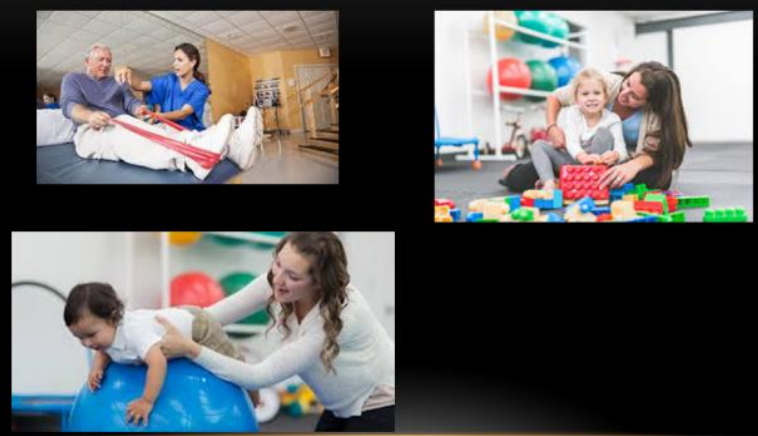

PURPOSE

- Identify a potential role for Occupational Therapy

- Identify potential occupational needs

- Observation / interviews

- Advocate potential OT role to various treatment centers.

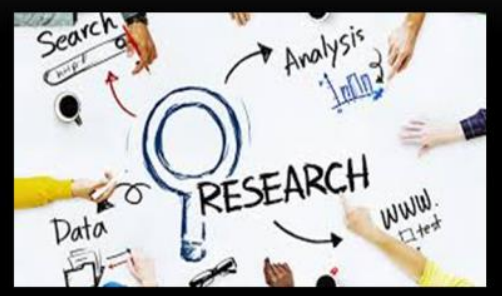




\section{WHAT DID I DO?}

- Gain insight/experiences on individuals in recovery

- Collected Data

- Filtered out appropriate information

- Participant Interviews

- Recorded and analyzed data

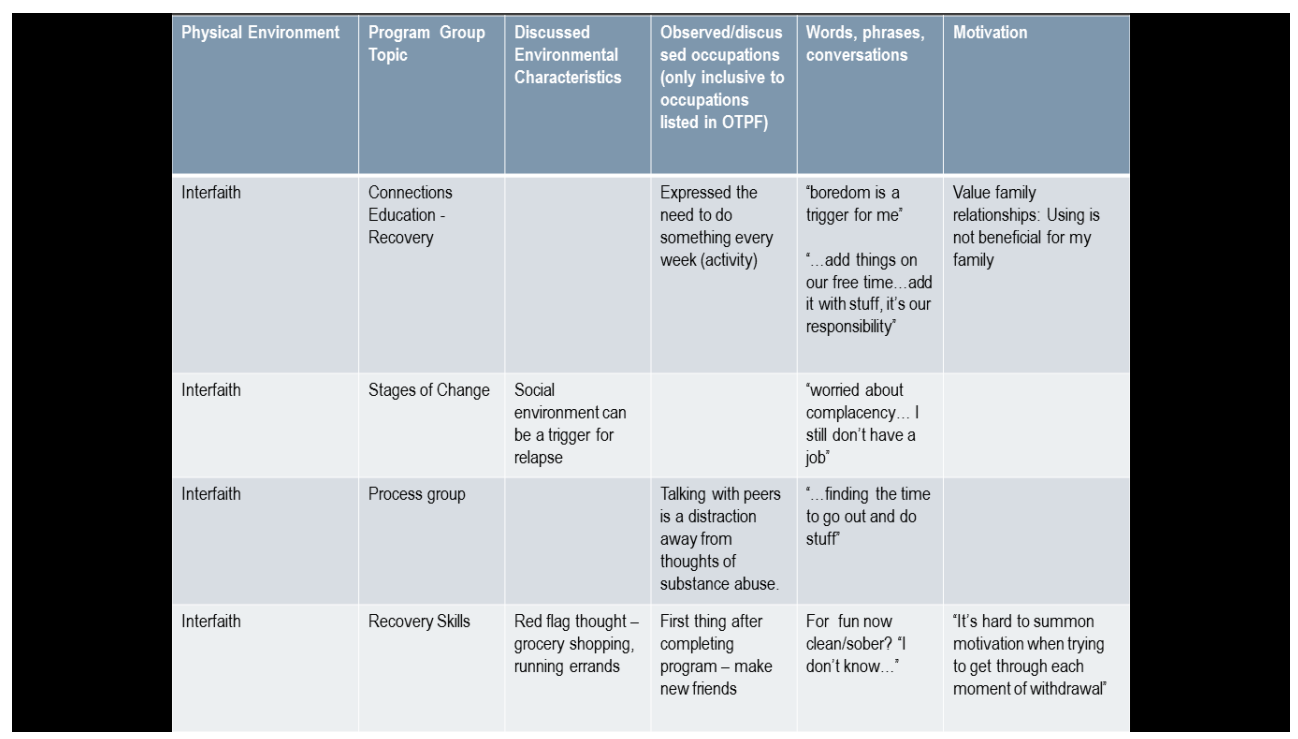

\section{LEISURE PROGRAM EXAMPLE}

- Leisure Exploration Group

- Purpose: Assist participants to explore and participate in meaningful leisure activities that will serve as a contributing factor in the recovery process.

- Group size: 3-8 participants

- Length: 4 week program

- Outcomes: Modified Canadian Occupation Performance Measure (COPM) 


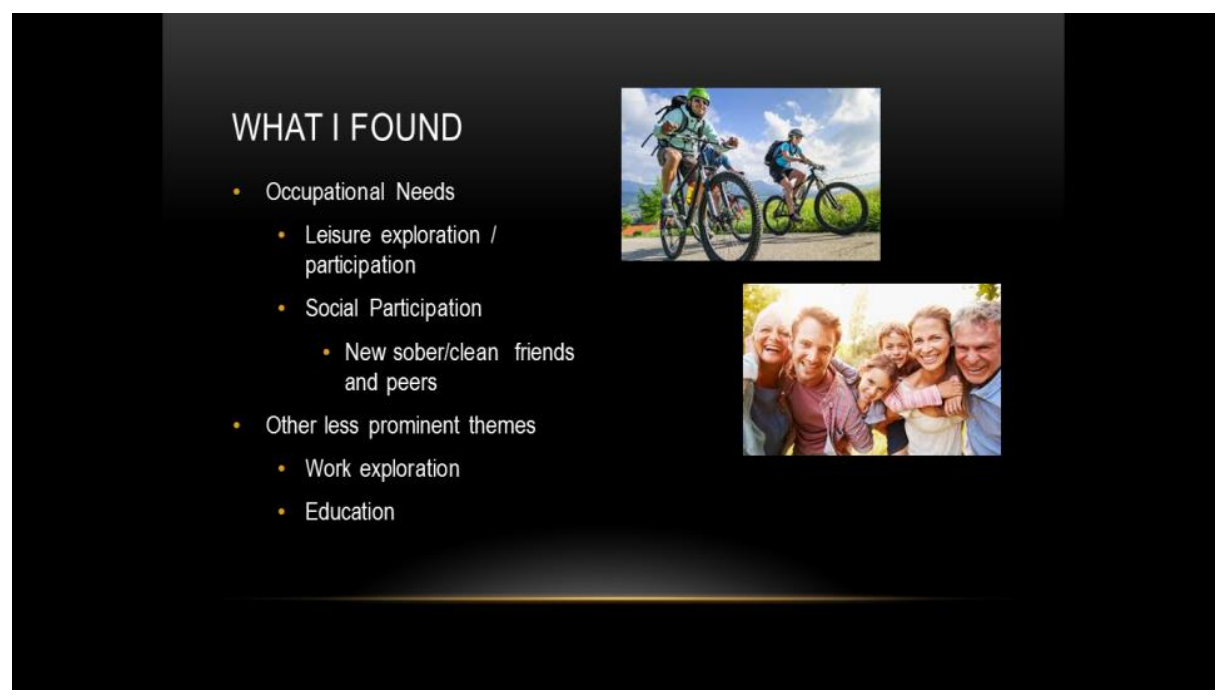

\section{LEISURE PROGRAM OUTLINE (EXAMPLE)}

\begin{tabular}{|l|l|}
\hline Week & Goal \\
\hline Week 1 & $\begin{array}{l}\text { - Identify potential leisure activities in group } \\
\text { setting }\end{array}$ \\
\hline Week2 & - Plan out leisure activity in group setting \\
\hline Week3 & $\begin{array}{l}\text { - Carry out leisure activities in controlled } \\
\text { environment with supervision }\end{array}$ \\
\hline
\end{tabular}

\section{LEISURE PROGRAM EXAMPLE}

- Leisure Exploration Group

- Purpose: Assist participants to explore and participate in meaningfu leisure activities that will serve as a contributing factor in the recovery process.

- Group size: 3-8 participants

- Length: 4 week program

- Outcomes: Modified Canadian Occupation Performance Measure (COPM) 
RECOMMENDED ACTION STEPS

- Collaborate with University of St. Augustine for Health Sciences Occupational Therapy Program.

- Students can implement leisure group activities / program.

- Hire an Occupational Therapist (OT) / Occupational Therapist Assistant (OTA)
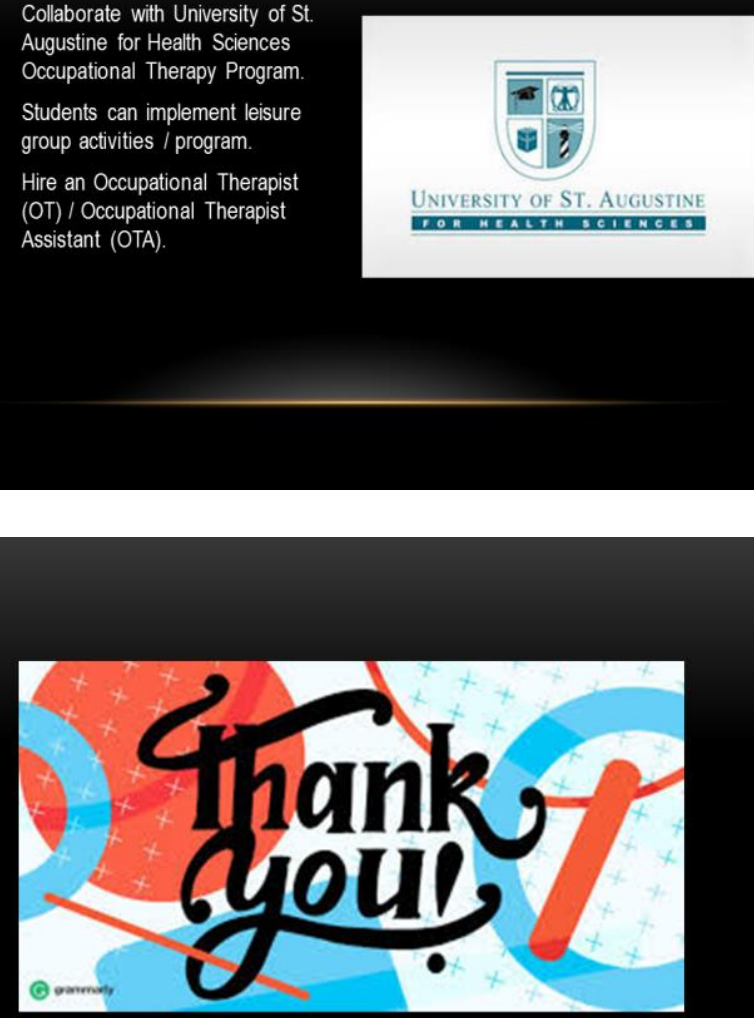

\section{REFERENCES}

Cole, M., (2017). Group Dynamics in Occupaiontal Therapy: The Theoretical Basis and Practice Application of Group Treatment ( $5^{\mathrm{h}}$ ed.). Thorofare, NJ: Slack. ISBN: 978 1630913670 


\section{APPENDIX D}

Evidence of Contact to other Residential Recovery Programs 


\begin{tabular}{|l|l|l|l|l|l|}
\hline Facility & $\begin{array}{l}\text { Type of } \\
\text { facility }\end{array}$ & Location & $\begin{array}{l}\text { Date of } \\
\text { contact }\end{array}$ & $\begin{array}{l}\text { Means of } \\
\text { contact }\end{array}$ & Notes \\
\hline Tru Vida Recovery & $\begin{array}{l}\text { Residential } \\
\text { Treatment / } \\
\text { IOP }\end{array}$ & $\begin{array}{l}\text { Lake } \\
\text { Forest, CA }\end{array}$ & $\begin{array}{l}\text { July } 25^{\text {th }}, \\
2019\end{array}$ & $\begin{array}{l}\text { Email 7/25 } \\
\text { Call 7/30 } \\
\text { Call 08/07 }\end{array}$ & $\begin{array}{l}\text { 07/30 \& 08/07 - } \\
\text { Contact } \\
\text { information given } \\
\text { to program director }\end{array}$ \\
\hline $\begin{array}{l}\text { Rancho Milagro } \\
\text { Recovery }\end{array}$ & $\begin{array}{l}\text { Residential } \\
\text { Treatment }\end{array}$ & $\begin{array}{l}\text { Temecula, } \\
\text { CA }\end{array}$ & $\begin{array}{l}\text { July } 25^{\text {th }}, \\
2019\end{array}$ & $\begin{array}{l}\text { Email 7/5 } \\
\text { Call 7/30 } \\
\text { Call 08/07 }\end{array}$ & $\begin{array}{l}07 / 30 \text { \& 08/07 - } \\
\text { Contact } \\
\text { information given } \\
\text { to program } \\
\text { director/manager }\end{array}$ \\
\hline $\begin{array}{l}\text { Ocean Hills } \\
\text { Recovery }\end{array}$ & $\begin{array}{l}\text { Residential } \\
\text { Treatment }\end{array}$ & $\begin{array}{l}\text { Dana } \\
\text { Point, } \\
\text { CA }\end{array}$ & $\begin{array}{l}\text { July } 25^{\text {th }}, \\
2019\end{array}$ & $\begin{array}{l}\text { Email 7/25 } \\
\text { Call 7/30 } \\
\text { Call 08/07 }\end{array}$ & $\begin{array}{l}\text { 07 /30 \& 08/07- } \\
\text { Contacted and left } \\
\text { message for } \\
\text { program director }\end{array}$ \\
\hline $\begin{array}{l}\text { Sanctuary } \\
\text { Treatment Center }\end{array}$ & $\begin{array}{l}\text { Detox \& } \\
\text { Inpatient } \\
\text { Addiction } \\
\text { Treatment }\end{array}$ & $\begin{array}{l}\text { Los } \\
\text { Angeles, } \\
\text { CA }\end{array}$ & $\begin{array}{l}\text { July 23 } \\
2019\end{array}$ & $\begin{array}{l}\text { Email 7/23 } \\
\text { Call 7/30 } \\
\text { Call 08/08 }\end{array}$ & $\begin{array}{l}\text { Call 07/30 - Line } \\
\text { busy } \\
\text { Call 08/08 - Email } \\
\text { provide reason and } \\
\text { purpose for contact }\end{array}$ \\
\hline $\begin{array}{l}\text { Broadway } \\
\text { Treatment Center }\end{array}$ & $\begin{array}{l}\text { Residential } \\
\text { Treatment } \\
\text { Center }\end{array}$ & $\begin{array}{l}\text { Huntington } \\
\text { Beach, CA }\end{array}$ & July 26, 2019 & $\begin{array}{l}\text { Email 7/26 } \\
\text { Email 08/08 }\end{array}$ & $\begin{array}{l}\text { 07/31 - preference } \\
\text { of contact via email } \\
\text { 08/08 - resend } \\
\text { email }\end{array}$ \\
\hline
\end{tabular}

